\title{
The causes of holes and loss of physical integrity in long-lasting insecticidal nets
}

\author{
Amy Wheldrake, Estelle Guillemois, Hamidreza Arouni, Vera Chetty and Stephen J. Russell
}

\begin{abstract}
Background: Long-lasting insecticidal nets (LLINS) are expected to last for at least 3 years, but whilst this may be achieved from an insecticidal perspective, physical protection is frequently compromised much earlier because of the rapid accumulation of holes during use. To understand why LLINs are so susceptible to loss of physical integrity, thousands of hole damage sites in LLINs retrieved from the field in Africa and Asia were forensically studied to identify the persistent underlying causes.

Methods: A total of 525 LLINs consisting of six different brands from five different countries across Africa and Asia were collected from the field after 1 to 3 years in use. More than 42,000 individual sites of hole damage were analysed based on the morphology and size of each individual hole, aided by optical microscopy (OM) and scanning electron microscopy (SEM). The fracture morphology enabled positive identification of the underlying mechanisms of the damage.

Results: Across all LLINs and geographical settings, mechanical damage is the primary cause of holes and loss of physical integrity in LLINs ( $63.14 \%$ by frequency and $81.52 \%$ by area). Snagging is the single most frequent mechanical damage mechanism, whilst the largest sized holes in LLINs result from seam failure and tearing. Abrasion and hole enlargement are also responsible for a progressive loss in the physical integrity of nets. Collectively, these five modes of mechanical damage can be expected to result from normal use of LLINs by households. Evidence of deliberate cutting, burn holes and rodent damage was observed to a lesser degree, which LLINs are not designed to withstand.
\end{abstract}

Conclusions: Loss of physical integrity in LLINs is an inevitable consequence of using a vector control product that has an inherently low resistance to mechanical damage during normal use. To improve performance, new specifications based on laboratory textile testing is needed, to assess the resistance of LLIN products to the primary causes of mechanical damage when in use, which are snagging, tearing, abrasion and hole enlargement. Seam construction also needs to meet a revised minimum standard to reduce the risk of a rapid loss of physical integrity during use.

Keywords: Long-lasting insecticide-treated nets, Physical integrity, Durability, Resistance to damage, Holes

\section{Background}

Long-lasting insecticidal nets (LLINs) are an established vector control tool responsible for saving many lives. According to the World Health Organization (WHO), cases of malaria fell $1.3 \%$ from 231 million in 2017 to 228 million in 2018 [1]. However, recent rises in

*Correspondence: stephenr@nonwovens-innovation.com Nonwovens Innovation \& Research Institute Ltd, 169 Meanwood Road, Leeds LS7 1SR, West Yorkshire, UK incidence have been linked to concerns about the condition and physical integrity of LLINs after a few years of use, and the potential for heightened risk of malaria transmission during the inter-campaign time period. It is now generally regarded as 'inevitable' that LLINs will accumulate holes as users interact with the product following distribution. Numerous field studies report accumulation of holes within the first two years of use, with many LLINs becoming so badly damaged that they are discarded [2-7], regardless of whether they still retain 
insecticidal functionality. Ideally, LLINs should provide physical protection for at least three years, but it is apparent that this is not being consistently achieved.

Until now, evaluations of the physical integrity of LLINs have relied on surveying the amount of damage they incur during use, by characterizing the location, size and frequency of holes $[8,9]$. It is apparent from these studies that while the relative degrees of damage may differ, all existing LLINs are susceptible to hole formation, irrespective of brand. The extent of damage in each setting is of course affected by a range of human behavioural and environmental factors, but there have been relatively few attempts to positively identify root cause mechanisms $[10,11]$. Previous efforts to identify the underlying causes of damage and hole formation in LLINs have mostly relied on user questionnaires and observations in the field [12]. These studies have attributed hole formation to a variety of factors including tearing, thermal damage due to candles or cooking embers and contact with rodents.

A forensic approach to identifying root causes was introduced by Käse and Russell based on direct microscopic analysis of hole damage sites in LLINs retrieved from the field in Africa [13]. The study, which looked at both PET and PE-based LLINs revealed three major causes of holes: (i) mechanical damage (in the form of snags, abrasion and tears), (ii) thermal damage (caused by proximity to naked flames and embers) and (iii) animal damage (rodent interaction). Mechanical damage was found to be the most frequent cause of holes, with the majority of the damage being consistent with normal use of the LLIN within households. To a limited extent, there was also evidence of deliberate damage to LLINs, such as where knives had been used to cut the net fabric, possibly to improve access. Therefore, when considering the holes accumulated during use, it was possible to distinguish between 'reasonable use' and 'unreasonable use' of the vector control product. In this context, reasonable use referred to forces and damage mechanisms that would be difficult to avoid if the LLIN was used as originally intended, whereas unreasonable use (or careless use) involved situations where there was exposure to mechanisms of damage that the product was never originally designed to resist.

The Käse and Russell [14] study involved a relatively small sample of LLINs retrieved from one geographical location in Africa, and a larger study is required to determine the extent to which findings are representative. In the present work, the primary causes of hole formation leading to loss of physical integrity in LLINs in large sample of over 500 LLINs retrieved from multiple settings across Africa and Asia, comprising multiple brands were identified. Understanding why holes form so easily during use is essential if underlying causes are to be addressed by an appropriate strategy to improve the physical integrity of LLINs.

\section{Methods}

The collection of nets from the field was overseen by Dr. A. Kilian with the kind assistance of Centers for Disease Control and Prevention (CDC), President's Malaria Initiative (PMI), WHO Pesticide Evaluation Scheme (WHOPES) and Tropical Health. A total of 525 LLINs made of polyethylene terephthalate (PET) or polyethylene (PE) were retrieved from the field in 2013, 1 to 3 years after use, across five different countries: India, Mozambique, Nigeria, Uganda and Kenya. Nets received from Nigeria were from three separate locations. Thus, a total of seven separate samples based on geographical location were included in the study. The sample comprised 163 Permanet nets (PET multifilament), 98 Olyset nets (PE monofilament), 139 Duranet nets (PE monofilament), 47 NetProtect nets (PE monofilament), 54 Dawaplus nets (PET multifilament) and 34 Interceptor nets (PET multifilament). The time in use ranged from 12 to 36 months.

Damage sustained by polymer and textile materials as a result of mechanical forces, heat and other agencies during use result in characteristic fracture morphologies that are extensively reported in the textile science literature [15-19]. Aided by optical microscopy (OM) and scanning electron microscopy (SEM), damage morphologies in all 525 LLINs (>40,000 holes) were individually analysed and categorized to determine root cause mechanisms. Examples of damage morphologies in LLINs and associated causes are summarized in Table 1. Holes associated with different damage mechanisms were counted and numerical frequency of their occurrence calculated.

Hole size was also measured to explore potential linkage with specific causes of damage. The Feret diameter (Fig. 1) was recorded, i.e. the distance tangential to the boundary of the hole at its largest dimension. Note that any break in a yarn within the LLIN fabric can be regarded as a hole defect and was therefore recorded. Total hole area was calculated as the sum of all hole areas attributed to an individual damage and across all analysed holes.

WHO guidelines recommend use of the proportionate hole index (PHI) to assess net fabric integrity [20]. The hole damage areas are expressed as a proportion of the total hole area. Hole size classification was based on WHO guidelines as summarized in Table 2. The hole index is based on the hole area as defined by the WHO hole size categories defined in Table 2. The hole index is then calculated by weighting each hole by size based on the hole area, as outlined in Table 2 , and summing values for each net. 
Table 1 Hole damage morphologies identified in LLINs retrieved from the field

\begin{tabular}{|c|c|c|}
\hline Type of damage & Damage morphology & Mechanism \\
\hline Snag & & $\begin{array}{l}\text { A yarn is pulled or plucked from the surface of the LLIN after becoming caught } \\
\text { on a solid pointed object }\end{array}$ \\
\hline Tear & & $\begin{array}{l}\text { Tensile breakage of yarns within the fabric plane, in one or more directions. For } \\
\text { example, after the LLIN is caught on a solid pointed object and then pulled in a } \\
\text { perpendicular direction }\end{array}$ \\
\hline Abrasion & & $\begin{array}{l}\text { Wearing away of yarns in the LLIN by rubbing against other surfaces. Broken fila- } \\
\text { ment ends project from the LLIN fabric surface }\end{array}$ \\
\hline Cut & & $\begin{array}{l}\text { Yarns are sliced by a knife or blade drawn through the structure. This involves } \\
\text { sharp transverse load and cleaved filament ends with limited distortion of the } \\
\text { LLIN fabric structure }\end{array}$ \\
\hline Thermal & & $\begin{array}{l}\text { Melting of the polymer in the yarn due to localised high temperature exposure. } \\
\text { Hard, melted and/or charred filament ends and shrinkage of the adjacent LLIN } \\
\text { fabric structure are typical }\end{array}$ \\
\hline Animal (rodent) & & $\begin{array}{l}\text { Shredded, frayed or ragged edged yarn breakages in the LLIN fabric, often com- } \\
\text { bined with discolouration, resulting from gnawing }\end{array}$ \\
\hline Seam failure & & $\begin{array}{l}\text { Breakage of the seam between two panels of the LLIN, leading to immediate } \\
\text { separation }\end{array}$ \\
\hline Laddering & & $\begin{array}{l}\text { Enlargement of an initial hole by pulling out of successive knitted loops in the } \\
\text { LLIN fabric structure following yarn breakage }\end{array}$ \\
\hline
\end{tabular}


Table 1 (continued)

Type of damage Damage morphology
Unravelling

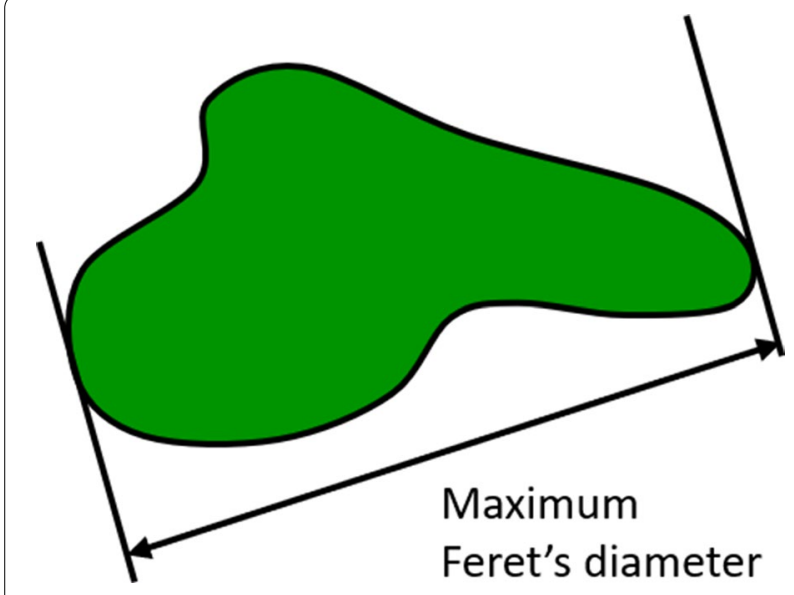

Fig. 1 Hole size by Feret's diameter

Thus, if the weighting of the hole sizes $1,2,3$ and 4 is 1 , 23, 196 and 576 respectively, the hole index $\left(\mathrm{H}_{\mathrm{i}}\right)$ per LLIN is calculated as in Eq. 1:

$$
\mathrm{H}_{i}=\left(1 \times \mathrm{N}_{1}\right)+\left(23 \times \mathrm{N}_{2}\right)+\left(196 \times \mathrm{N}_{3}\right)+\left(576 \times \mathrm{N}_{4}\right)
$$

where $\mathrm{N}_{1}$ is the number of size 1 holes, $\mathrm{N}_{2}$ is the number of size 2 holes, $\mathrm{N}_{3}$ is the number of size 3 holes and $\mathrm{N}_{4}$ is the number of size 4 holes.

\section{Results}

The hole morphologies summarized in Table 1 were found to accurately represent the full range of damage types observed in retrieved LLINs irrespective of brand or retrieval location. For all LLINs, the proportion of all holes attributable to each of these damage mechanisms was determined, both in terms of numerical frequency as well as their size.

\section{Damage mechanisms by hole frequency}

Holes in all LLINs resulted from combinations of mechanical, thermal or animal damage. Of these, mechanical damage consistently accounted for the majority of holes $(63.14 \%)$ by frequency, followed by animal (rodent) and thermal damage at approximately $28.87 \%$ and $8.99 \%$, respectively (Table 3 ). As shown in

Table 3 Damage mechanisms ranking and proportion of hole damage by frequency in LLINs caused by damage mechanisms

\begin{tabular}{lll}
\hline $\begin{array}{l}\text { Ranking of damage mechanism } \\
\text { by hole frequency }\end{array}$ & Cause & $\begin{array}{l}\text { Proportion } \\
\text { by frequency } \\
\text { (\%) }\end{array}$ \\
\hline 1 & Mechanical & 63.14 \\
2 & Animal & 27.87 \\
3 & Thermal & 8.99 \\
\hline
\end{tabular}

Table 2 WHO hole size guidelines and hole index used to assess physical integrity of LLINs

\begin{tabular}{|c|c|c|c|c|c|c|}
\hline \multirow[t]{2}{*}{ WHO 2013 guidelines } & \multirow{2}{*}{$\begin{array}{l}\text { Size banding } \\
\mathrm{cm}\end{array}$} & \multirow{2}{*}{$\begin{array}{l}\text { Hole diameter } \\
\text { d; cm }\end{array}$} & \multicolumn{2}{|l|}{ Hole radius } & \multirow{2}{*}{$\begin{array}{l}\text { Area of hole } \\
\mathrm{cm}^{2}\end{array}$} & \multirow[t]{2}{*}{ Hole index ${ }^{a}$} \\
\hline & & & $\mathrm{r}=\mathrm{d} / 2 ; \mathrm{cm}$ & $\mathrm{r}^{2} ; \mathrm{cm}^{2}$ & & \\
\hline $\begin{array}{l}\text { Size } 1 \\
\text { Smaller than a thumb }\end{array}$ & $0.5-2$ & 1.25 & 0.625 & 0.3906 & 1.23 & 1 \\
\hline $\begin{array}{l}\text { Size } 2 \\
\text { Larger than a thumb but smaller than a fist }\end{array}$ & $2.5-10$ & 6 & 3 & 9 & 28.28 & 23 \\
\hline $\begin{array}{l}\text { Size } 3 \\
\text { Larger than a fist but smaller than a head }\end{array}$ & $11-25$ & 17.5 & 8.75 & 76.5625 & 240.56 & 196 \\
\hline $\begin{array}{l}\text { Size } 4 \\
\text { Larger than a head }\end{array}$ & $\geq 26$ & $30^{b}$ & 15 & 225 & 706.95 & 576 \\
\hline
\end{tabular}

A -area of the hole $\mathrm{pr}^{2} ; \mathrm{p}=3.142$

a Area divided by 1.23

b Assumer diameter 
Fig. 2, the mechanical damage in LLINs could be further broken down into five recurrent mechanisms: snagging, tearing, abrasion, seam failure and cutting. Secondary damage such as laddering and unravelling were associated with hole enlargement following the initial mode of failure.

All LLINs were susceptible to mechanical damage with snags being by far the most frequently encountered mechanism, responsible for $42.03 \%$ of the total number of holes present (Fig. 2). The second most frequent cause of mechanical damage was abrasion (12\%). Tears, seam failure and cuts accounted for less than $10 \%$ of the total damage by numerical frequency, lower than thermal damage (8.99\%), and animal (rodent) damage (27.87\%).

\section{Damage mechanisms by hole area and size}

When considered in terms of total hole area, mechanical damage was again responsible for the largest proportional total hole area (81.5\%) across all LLINs (Table 4), followed by animal (rodent) and thermal damage (10.6\% and $7.9 \%$, respectively). Interestingly, Fig. 3 reveals that the less numerically frequent forms of hole damage reported in Fig. 2, were responsible for the largest hole sizes. While tears and seam failure were relatively infrequent, compared to for example, snags (Fig. 2), these two mechanisms resulted in the largest hole areas, and produced the largest individual hole diameters, with median values of $5 \mathrm{~cm}$ and $6 \mathrm{~cm}$ respectively (Fig. 3).

Despite their high numerical frequency (Fig. 2), snag and animal (rodent) hole damage each accounted for only small proportion (about 11\%) of the total hole damage by area in LLINs, while the smallest hole area
Table 4 Damage mechanisms ranking and proportion of total hole area in LLINs caused by damage mechanisms

\begin{tabular}{lll}
\hline $\begin{array}{l}\text { Ranking of damage } \\
\text { mechanism } \\
\text { by hole area }\end{array}$ & Cause & $\begin{array}{l}\text { Proportion } \\
\text { of total hole } \\
\text { area (\%) }\end{array}$ \\
\hline 1 & Mechanical & 81.52 \\
2 & Animal & 10.63 \\
3 & Thermal & 7.86 \\
\hline
\end{tabular}

was associated with abrasion (3.7\%) (Fig. 4). This is linked to the fact that the most frequent holes resulting from snagging, animal damage and abrasion resulted in very small median hole sizes of only $\sim 1 \mathrm{~cm}$. Tearing was responsible for $35.61 \%$ of the total hole area (Fig. 4), followed by seam failure (16.47\%) and cuts $(14.22 \%)$. Seam failure was also associated with the largest range of hole sizes, with some reaching $15 \mathrm{~cm}$ in diameter (Fig. 3), so large in fact that the physical protection offered by these LLINs could be considered questionable.

As is also evident in Fig. 3, cuts and thermal damage produced relatively small holes (median $=1 \mathrm{~cm}$ and $1.5 \mathrm{~cm}$, respectively) but there was greater size variation than with snags, rodent and abrasion hole damage.

The proportion of the total hole area caused by each of the damage mechanisms was further investigated with regard to specific countries. Regardless of where the LLINs were distributed and how the LLINs had been constructed, mechanical damage accounted for more than $64 \%$ of the total hole surface area for each country as illustrated in Fig. 5.

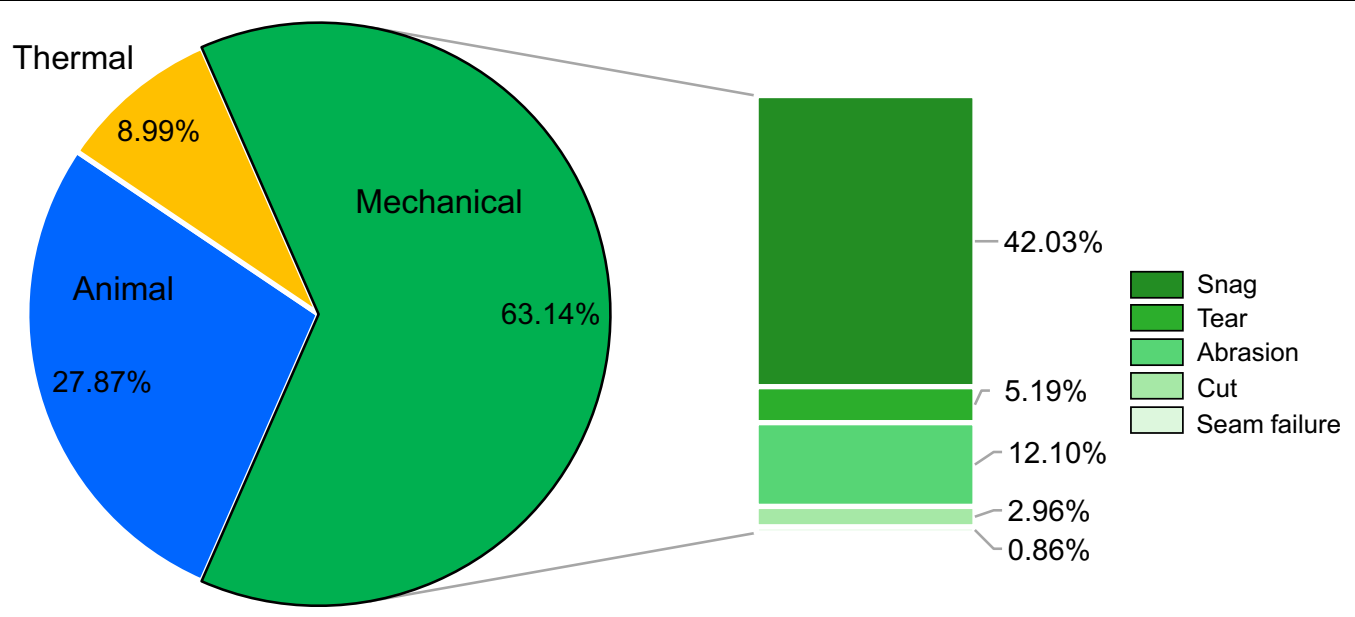

525 nets - 52\% PE monofilament / 48\% PET multifilament

Fig. 2 Proportion of holes by frequency in all analysed LLINs caused by the specific damage mechanisms 


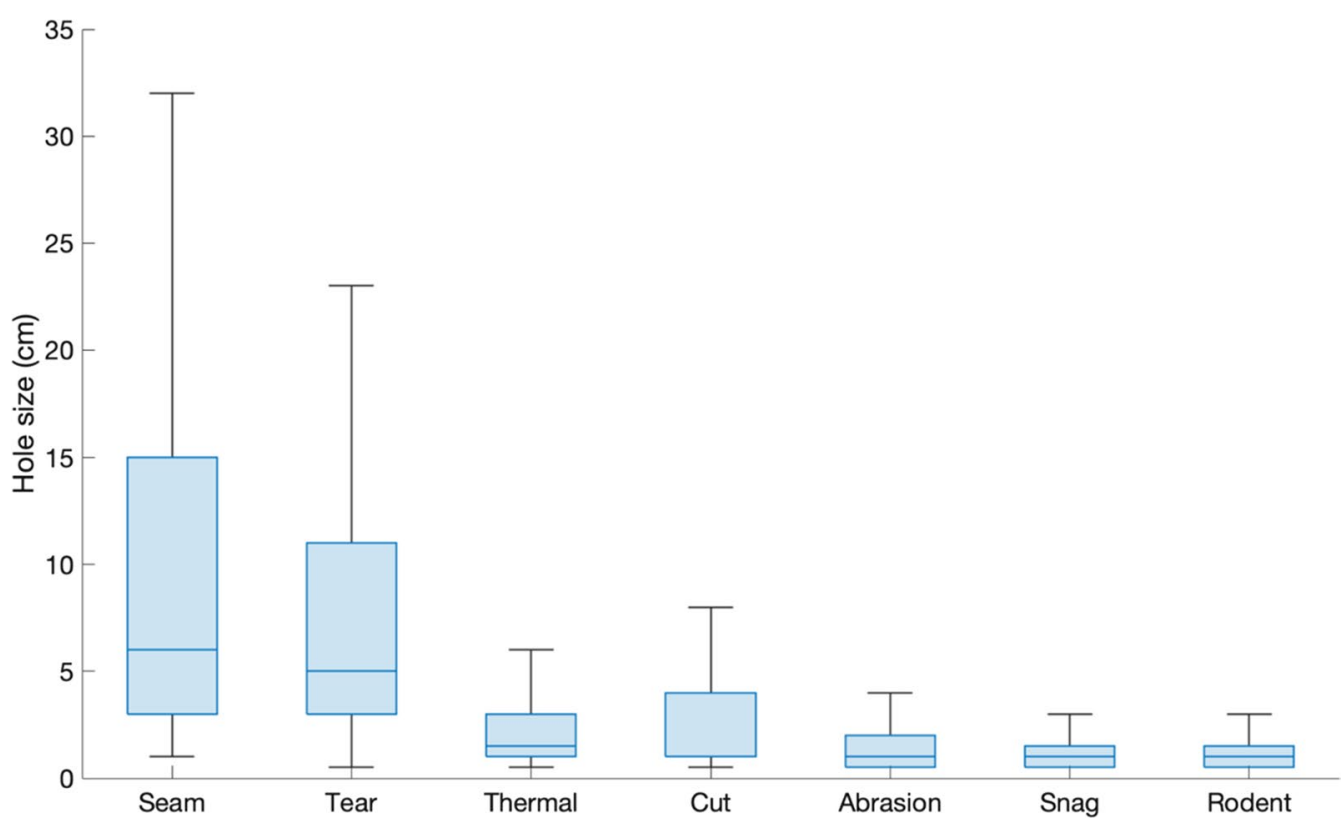

Fig. 3 Box plot of the hole size for specific hole damage mechanisms

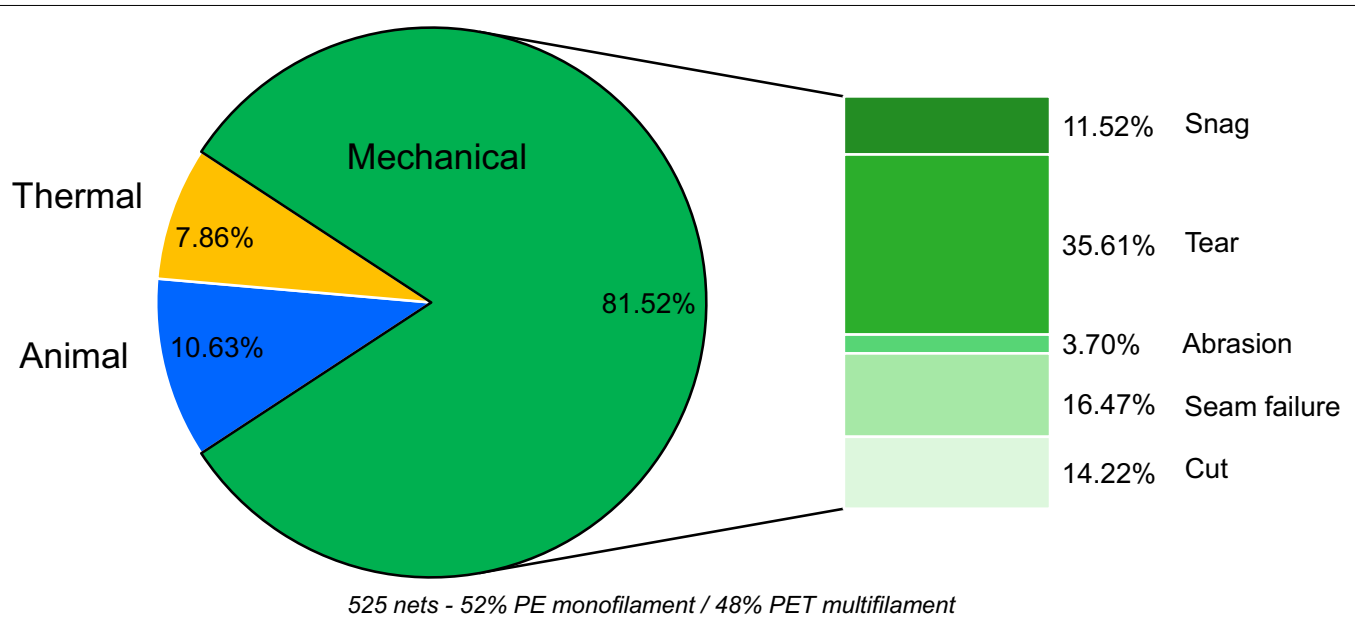

Fig. 4 Proportion of total hole area in LLINs collected in different countries caused by damage mechanisms

\section{Proportional hole index}

PHI is a particularly useful indicator of the relative magnitude of LLIN damage because it is influenced by both hole size and frequency. In this study, it was possible for the first time to attribute PHI values to specific hole damage mechanisms. For this analysis, to give an insight in to inherent differences in the resistance to damage of LLIN products made in different ways, PHI values were calculated for six different LLIN products (retrieved from the same location, after the same period of use). This sample consisted of LLINs made from $48 \%$ of PET multifilament yarns and 52\% of PE monofilament yarns (Table 5). To gain an insight into the inherent ability of different LLINs to withstand the agencies of wear and tear normally encountered during household use, only mechanical hole damage in the LLINs due to reasonable use was considered in the PHI data, i.e. snagging, tearing and abrasion. Hole formation due to seam failure was not included in the investigation as poorly constructed seams is possible irrespective of type of filament yarn and net structure. 


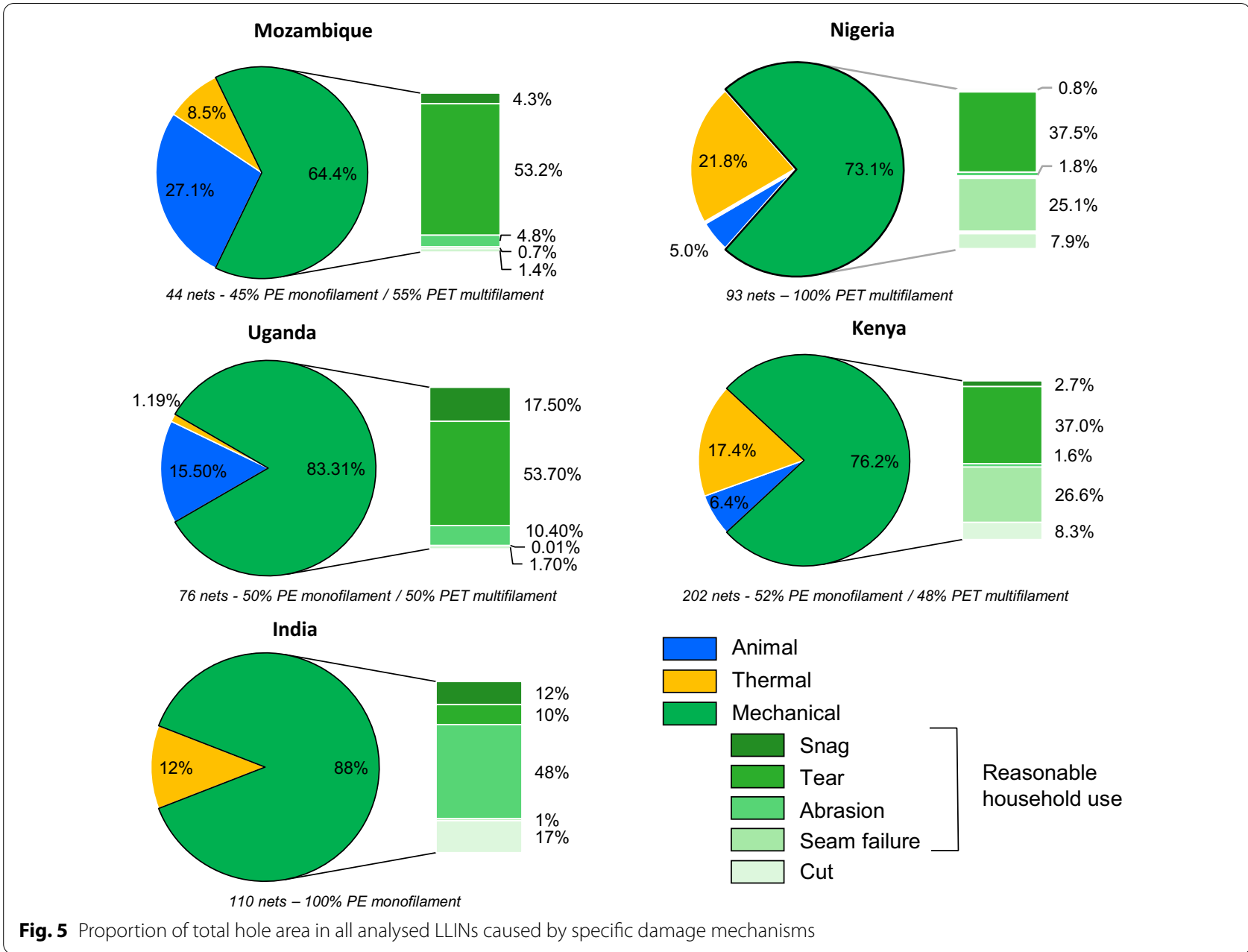

Table 5 Number of holes per size category for all LLINs and mean PHI per LLIN

\begin{tabular}{|c|c|c|c|c|c|}
\hline \multirow{2}{*}{$\begin{array}{l}\text { Filament specification and LLIN fabric } \\
\text { knitting pattern }\end{array}$} & \multicolumn{4}{|c|}{ Number of holes per size category for all LLIN } & \multirow[t]{2}{*}{ Mean PHI per LLIN } \\
\hline & Size 1 & Size 2 & Size 3 & Size 4 & \\
\hline All PET multifilament nets & 1954 & 367 & 57 & 23 & 363 \\
\hline All PE monofilament nets & 1083 & 219 & 51 & 24 & 282 \\
\hline $\begin{array}{l}145 \text { Denier } \\
\text { PE monofilament—knitting pattern } 1\end{array}$ & 308 & 45 & 5 & 4 & $\begin{array}{c}160 \\
\text { (lowest PHI) }\end{array}$ \\
\hline $\begin{array}{l}75 \text { D or } 100 \mathrm{D} \\
\text { PET multifilament—-knitting pattern } 2\end{array}$ & 739 & 155 & 21 & 14 & $\begin{array}{c}485 \\
\text { (highest PHI) }\end{array}$ \\
\hline
\end{tabular}

Table 5 reveals that LLINs made from PE monofilament yarns exhibited lower PHI values in the Size 1 and 2 categories $(1083,219)$ compared to PET multifilament nets (1954, 367). Referring to Fig. 3, hole sizes of $0.5-2 \mathrm{~cm}$ (size 1) relate to holes caused by snagging and abrasion while hole sizes of $4-8.5 \mathrm{~cm}$ (size 2) relate to tear damage. The marked difference in the PHI for the size 1 category, can be attributed to multifilament yarns being more prone to snagging on solid objects and abrasion, compared to those made from monofilament. The difference is therefore attributable mainly to the type of filament yarn (monofilament, multifilament) used to make the LLIN and not the polymer composition (PET, PE).

All LLINs regardless of knitting pattern and filament linear density (denier) suffered hole formation across all PHI size categories, due to mechanical damage, reflecting 
a progressive loss of physical integrity over a period of use. However, from Table 5 it was apparent that some LLIN products were more resistant to mechanical damage than others. Across all size ranges (PHI size 1-4), the knitting pattern 1 LLIN structure made of 145 denier PE monofilament yarns consistently produced the lowest number of holes in each size category, compared to the knitting pattern 2 structure made of 75 or 100 denier PET multifilament yarns.

\section{Hole enlargement}

Regardless of their initial dimensions, it is known that existing holes in LLINs can enlarge into bigger ones [13] during subsequent use, producing characteristic damage morphology (Table 1). Even a single yarn breakage in a LLIN can be sufficient to seed the formation of a larger hole due to secondary damage such as laddering or unravelling of the fabric structure. Laddering and unravelling defects were observed in many of the LLINs (Table 6). Unlike tearing, unravelling does not require yarns to progressively break, but rather disassembly of the net structure occurs following an initial break of a yarn, as knitted loops slip apart. This has the capacity to produce large holes and is heavily influenced by the choice of knitting pattern used to make the LLIN.

Consequently, small initial hole damage in LLINs such as that created by snags is important because even one yarn breakage could be sufficient to seed the formation of a larger hole later.

\section{Discussion}

Effective, long-lasting insecticides [21-23] are essential to the future of vector control, but these efforts are likely to be seriously undermined if the physical integrity of LLINs does not markedly improve [24-26]. In this study, the primary causes of holes and thereby loss of physical integrity in LLINs were identified, so as to understand why these important vector control products are prone to rapid deterioration after only a few years of use. It was discovered that mechanical damage is the primary cause of hole formation in all LLINs both in terms of frequency (63.14\%, Table 3; Fig. 2) and total hole area (81.52\%, Table 4; Fig. 4), confirming the previous findings of

Table 6 Proportion of holes exhibiting secondary damage by frequency in all analysed LLINs

\begin{tabular}{llll}
\hline Population & $\begin{array}{l}\text { \% of holes } \\
\text { exhibiting } \\
\text { unravelling } \\
\text { and tearing }\end{array}$ & $\begin{array}{l}\text { \% of holes } \\
\text { exhibiting } \\
\text { laddering }\end{array}$ & $\begin{array}{l}\text { \% of ladders } \\
\text { combined } \\
\text { with tearing }\end{array}$ \\
\hline $\begin{array}{l}\text { Total across all } \\
\text { LLINs }\end{array}$ & 5.41 & 6.13 & 18.11 \\
\hline
\end{tabular}

Russell and Käse, whose findings were based on a smaller sample size, and confined to a retrieval site in South East Ghana [13].

Although mechanical damage caused by snagging produced small holes (Fig. 3), it was by far the most frequent cause of damage in all LLINs (Fig. 2), highlighting the high susceptibility of net fabrics to this form of physical deterioration. Snagging is a well-known deficiency of lightweight knitted fabrics, which are now typically less than $55 \mathrm{~g} / \mathrm{m}^{2}$ [27], and damage can only be expected to worsen if LLIN fabric weights decrease. LLIN fabrics made of multifilament yarns were more prone to snagging than those made from monofilaments, which had the effect of increasing the PHI due to the frequency of holes in the size 1 category (Table 5). As in the case of mechanical damage in the form of snagging, abrasion resulted in relatively small holes ranging in size from 0.5 to $2 \mathrm{~cm}$ (Fig. 3). This results from progressive abrasive wear of the yarns in the LLIN fabric as they are rubbed against a solid surface resulting ultimately in yarn breakage. Although the small holes that snagging and abrasion produces may not initially compromise the physical protection provided by the LLIN, there is a risk of hole enlargement during subsequent use, as confirmed by Table 6 , due to unravelling or laddering.

The largest holes found in LLINs were caused by seam failure and tearing (Fig. 3), both of which are forms of mechanical damage. Together these two mechanisms accounted for over $50 \%$ of the total hole area in LLINs (Fig. 4). Seam failure in this context primarily results from poor manufacturing practice, because in certain seam constructions, the breakage of just one yarn within the seam can lead to rapid separation of the LLIN panels, rendering it essentially useless in terms of physical protection. Seam failure can be largely mitigated by ensuring LLINs are made with appropriate seam constructions in the first place. Tearing also produces large holes and accounted for more than 35\% of the total hole area in LLINs (Table 4). Tears usually form as a result of the net first being snagged on a solid object, such as wooden mattress material, and then when force is applied to pull it free, tearing is induced as individual yarns break. Polymer, yarn and fabric properties, as well as the basis weight of the LLIN fabric will all influence the susceptibility of the LLIN fabric to tearing.

Efforts to limit the rate of physical deterioration of LLINs depend on future products having significantly improved resistance to the mechanical damage during reasonable use in the household and/or being used more carefully. Clearly, the former depends on improved LLIN product design and appropriate technical specifications, and the latter depends on behavioural change. Behavioural change will require 
promoting careful deployment, utilisation and storage of LLINs by users (primarily), regular repair and maintenance and keeping nets clean to reduce the need for washing [28]. Keeping nets away from candles, cooking embers and cigarettes, as well as preventing their misuse for purposes, such as food storage, fishing or other means of use different from the intended vector protection is also important. However, more careful use, is unlikely to be sufficient on its own to address the challenge, unless the basic 'resistance to damage' of current LLIN vector control products is significantly improved. Even if LLINs are used relatively carefully, mechanical damage is highly likely to accumulate, and rate of attritional wear would be expected to be greater if there are children in the household or nets are not looked after properly [10].

Given the real-world conditions that LLINs and users face, more physically robust LLINs are needed to reduce hole formation and enable significant improvements in long-term physical integrity and durability to be achieved. This means designing and specifying LLIN vector control products that are better able to cope with the normal agencies of mechanical wear and tear they will encounter during reasonable household use. Specifically, this means designing improved LLIN products with the capability to resist snagging, tearing, seam failure, abrasion and hole enlargement. For economic reasons alone, it would be highly challenging to design cost-effective LLIN products with the ability to resist unreasonable use resulting from cutting, rodent interactions or high temperature thermal damage. However, a combined approach of implementing products with higher inherent resistance to mechanical damage, together with behavioural change measures, is likely to be an effective strategy for improving the longterm physical integrity of LLINs.

It is apparent from the present work that LLINs are subjected to a group of forces during normal household use, that are not reflected in product specifications prior to distribution. Currently, the only routine laboratory test conducted on LLINs to evaluate their resistance to damage is bursting strength, which as a sole measure of mechanical strength, does not fully reflect the real mechanisms by which LLINs are deteriorating in users' households. Of the mechanical damage observed in LLINs associated with reasonable use of the product, it is believed that approximately $80 \%$ is preventable by improved design and specification of the LLIN itself. Resistance to snagging, tearing, abrasion, seam failure and hole enlargement can all be improved and should be tested in the laboratory to make sure the physical condition of LLINs is less susceptible to deterioration before distribution to vulnerable users.

\section{Conclusions}

Mechanical damage is the primary cause of hole formation and loss of physical integrity in LLINs, whether expressed in terms of frequency or area $(63.14 \%$ and $81.52 \%$, respectively). Regardless of where the LLINs were distributed, mechanical damage accounted for more than $64 \%$ of the total hole area in LLINs. This relates to a group of damage mechanisms that LLINs are exposed to during normal household use: snagging, tearing, abrasion and hole enlargement. Increasing the inherent resistance of LLINs to these specific forms of mechanical damage is likely to substantially reduce their susceptibility to hole formation, thereby improving long-term physical integrity. The largest holes in LLINs are attributable to tearing and seam failure, the latter being indicative of poor manufacturing practice, but small holes should also not be ignored because of their potential to enlarge over time. To increase physical integrity, the inherent resistance to mechanical damage of LLIN vector control product needs to be improved. Seam construction requires a new minimum standard, and all LLIN fabrics should be subjected to a suite of textile tests to evaluate and specify their snag strength, tear strength, abrasion resistance and resistance to hole enlargement.

\section{Acknowledgements \\ The authors acknowledge the contribution of Bill \& Melinda Gates Foundation for the financial support. This study summarizes the findings and recommen- dations from a two-phase study undertaken by Nonwovens Innovation and Research Institute (NIRI), Tropical Health LLP (led by Albert Kilian), and Results for Development Institute (R4D). \\ Authors' contributions \\ AW and SR designed the study, developed the test methods and contributed to the preparation of the manuscript. AW conducted the experimental work. EG contributed to the data analysis and preparation of the manuscript; HA contributed to the data analysis and the preparation of the manuscript; VC contributed to the data analysis and to the final manuscript. All authors read and approved the final manuscript.}

\section{Competing interests}

The authors declare that they have no competing interests.

Received: 11 September 2020 Accepted: 22 December 2020

Published online: 19 January 2021

\footnotetext{
References

1. WHO. World malaria report 2019. Geneva: World Health Organization; 2019.

2. Randriamaherijaona S, Raharinjatovo J, Boyer S. Durability monitoring of long-lasting insecticidal (mosquito) nets (LLINs) in Madagascar: physical integrity and insecticidal activity. Parasit Vectors. 2017;10:564.

3. Gnanguenon V, Azondekon R, Oke-Agbo F, Beach R, Akogbeto M. Durability assessment results suggest a serviceable life of two, rather than three, years for the current long-lasting insecticidal (mosquito) net (LLIN) intervention in Benin. BMC Infect Dis. 2014;14:69.

4. Hakizimana E, Cyubahiro B, Rukundo A, Kabyiza A, Mutabazi A, Beach R, et al. Monitoring long-lasting insecticidal net (LLIN) durability to validate net serviceable life assumptions, in Rwanda. Malar J. 2014;13:344.
} 
5. Massue DJ, Moore SJ, Mageni ZD, Moore JD, Bradley J, Pigeon O, et al. Durability of Olyset campaign nets distributed between 2009 and 2011 in eight districts of Tanzania. Malar J. 2016;15:176.

6. Lorenz LM, Overgaard HJ, Massue DJ, Mageni ZD, Bradley J, Mandike R, et al. Investigating mosquito net durability for malaria control in Tanzania - Attrition, bioefficacy, chemistry, degradation and insecticide resistance (ABCDR): Study protocol. BMC Public Health. 2014;14:1266.

7. Haji KA, Khatib BO, Obi E, Dimoso K, Koenker H, Babalola S, et al. Monitoring the durability of the long-lasting insecticidal nets Olyset ${ }^{\circledR}$ and PermaNet ${ }^{\circledR} 2.0$ in similar use environments in Zanzibar. Malar J. 2020;19:187.

8. Boussougou-Sambe ST, Awono-Ambene P, Tasse GCT, Etang J, Binyang JA, Nouage LD, et al. Physical integrity and residual bio-efficacy of used LLINs in three cities of the South-West region of Cameroon 4 years after the first national mass-distribution campaign. Malar J. 2017;16:31.

9. Dutta SN, Amon J, lata H, Cooper RD, Russell TL. Long-term insecticidal activity and physical integrity of Olyset nets in Tafea Province,\&nbsp;Vanuatu. J Med Entomol. 2014;51:164-9.

10. Kilian A, Koenker $\mathrm{H}$, Obi E, Selby RA, Fotheringham M, Lynch M, et al. Field durability of the same type of long-lasting insecticidal net varies between regions in Nigeria due to differences in household behaviour and living conditions. Malar J. 2015;14:123.

11. Ahogni IB, Aïkpon RY, Ossè RA, Dagnon JF, Govoetchan R, Attolou RH, et al. Field durability of Yorkool ${ }^{\circledR}$ LN nets in the Benin Republic. Adv Entomol. 2020:8:72-92.

12. WHO. Guidelines for monitoring the durability of long-lasting insecticidal mosquito nets under operational conditions. WHOPES, Global Malaria Programme Vector Control Unit. Geneva: World Health Organization; 2011.

13. Käse SK, Russell SJ. Modes of hole formation in long-lasting insecticidal nets (LLINs) retrieved from South Eastern Ghana. Parasit Vectors. 2014;7:547.

14. Jyo A, Kugara J, Trobradovic H, Yamabe K, Sugo T, Tamada M, et al. Fibrous iminodiacetic acid chelating cation exchangers with a rapid adsorption rate. Ind Eng Chem Res. 2004;43:1599-607.

15. Hearle JWS. Atlas of fibre fracture and damage to textiles. 2nd ed. Cambridge: Woodhead Publishing Ltd; 1998.

16. Heuse O. Damage to clothing caused by stabbing tools. Arch Kriminologie. 1982;170:129-45.

17. Johnson N. Physical damage to textiles. Asia Pacific Police Technol Conf. 1991.

18. Monahan DL, Harding HWJ. Damage to clothing-cuts and tears. J Forensic Sci. 1990;35:901-12.
19. Horrocks AR, Price D, Tunc M. The burning behaviour of textiles and its assessment by oxygen-index methods: a critical appreciation of recent developments. (Cegielka L, editor). Textile Institute, Manchester; 1989.

20. WHO. Guidelines for laboratory and field testing of long-lasting insecticidal mosquito nets. Geneva: World Health Organization; 2005. http:// whqlibdoc.who.int/hq/2005/WHO_CDs_WHOPES_GCDPP_2005.11.pdf.

21. Toé KH, Mechan F, Tangena JAA, Morris M, Solino J, Tchicaya EFS, et al. Assessing the impact of the addition of pyriproxyfen on the durability of permethrin-treated bed nets in Burkina Faso: a compound-randomized controlled trial. Malar J. 2019;18:383.

22. Camara S, Ahoua Alou LP, Koffi AA, Clegban YCM, Kabran JP, Koffi FM, et al. Efficacy of Interceptor ${ }^{\circledR} \mathrm{G} 2$, a new long-lasting insecticidal net against wild pyrethroid-resistant Anopheles gambiae s.s. from Côte d'Ivoire: a semi-field trial. Parasite. 2018;25:42.

23. Chinula D, Sikaala CH, Chanda-Kapata P, Hamainza B, Zulu R, Reimer L, et al. Wash-resistance of pirimiphos-methyl insecticide treatments of window screens and eave baffles for killing indoor-feeding malaria vector mosquitoes: an experimental hut trial, South East of Zambia. Malar J. 2018;17:164.

24. Shah MP, Steinhardt LC, Mwandama D, Mzilahowa T, Gimnig JE, Bauleni A, et al. The effectiveness of older insecticide-treated bed nets (ITNs) to prevent malaria infection in an area of moderate pyrethroid resistance: results from a cohort study in Malawi. Malar J. 2020;19:24

25. Randriamaherijaona S, Briët OJT, Boyer S, Bouraima A, N'Guessan R, Rogier C, et al. Do holes in long-lasting insecticidal nets compromise their efficacy against pyrethroid resistant Anopheles gambiae and Culex quinquefasciatus? Results from a release-recapture study in experimental huts. Malar J. 2015;14:332.

26. Nonaka D, Maazou A, Yamagata S, Oumarou I, Uchida T, Jg Yacouba H, et al. Can long-lasting insecticide-treated bednets with holes protect children from malaria? Trop Med Health. 2014;42:99-105.

27. El-Shiekh A, Backer S. The mechanics of snagging in plain-knitted structures. Text Res J. 1973;43:262-71.

28. Helinski MH, Namara G, Koenker H, Kilian A, Hunter G, Acosta A, et al. Impact of a behaviour change communication programme on net durability in eastern Uganda. Malar J. 2015;14:366.

\section{Publisher's note}

Springer Nature remains neutral with regard to jurisdictional claims in published maps and institutional affiliations.
Ready to submit your research? Choose BMC and benefit from:

- fast, convenient online submission

- thorough peer review by experienced researchers in your field

- rapid publication on acceptance

- support for research data, including large and complex data types

- gold Open Access which fosters wider collaboration and increased citations

- maximum visibility for your research: over $100 \mathrm{M}$ website views per year

At BMC, research is always in progress.

Learn more biomedcentral.com/submissions 